\title{
Lower limb arterial injuries-etiology, presentations, management and outcome: A center's experience
}

\author{
Ahmed M.E.E. Osman, Saif Eldin Mohammed Ali Ibrahim, \\ Ashraf Mohammed Mokhtar, Ghofran Mahgoub Hussien Mohamed, \\ Sara Mohammed Yassin Hassan, Tasneem Elrayah Ramli Ahmed, \\ Abubakr Hashim Elrofaie Sayed Ali
}

\begin{abstract}
Aims: Vascular injuries are encountered in a vast number of settings, ranging from stab wounds and bullet injuries, to causes as small as arterial blood sampling procedures. Surgery for vascular repair is sometimes indicated without angiography. Broadly speaking, options for repair after assessment of vasculature include simple vessel wall repair, venous patching; resection with end-to-end anastomosis or with interpositioning graft, bypass graft, ligation or amputation. General objective of this study is to identify the etiology, presentations, management and outcome of lower limb arterial injuries in Khartoum, Sudan, From September 2013 to September 2014. Methods: Retrospective hospital based study and the study population
\end{abstract}

Ahmed M.E.E. Osman¹, Saif Eldin Mohammed Ali Ibrahim², Ashraf Mohammed Mokhtar ${ }^{3}$, Ghofran Mahgoub Hussien Mohamed $^{4}$, Sara Mohammed Yassin Hassan ${ }^{1}$, Tasneem Elrayah Ramli Ahmed ${ }^{1}$, Abubakr Hashim Elrofaie Sayed Ali ${ }^{1}$

Affiliations: ${ }^{1}$ MBBS, Resident, Unit of Vascular and Endovascular Surgery, Ibn Sina Specialized Hospital, Khartoum, Sudan; ${ }^{2}$ MD, MRCS (Eng.), D.MAS, F.MAS, F.Vasc/Endovasc (MAL), Head, Unit of Vascular and Endovascular Surgery, Ibn Sina Specialized Hospital, Khartoum, Sudan; ${ }^{3} \mathrm{MD}$, General Surgery, Unit of Vascular and Endovascular Surgery, Ibn Sina Specialized Hospital, Khartoum, Sudan; 'MBBS, MRCS, Resident, Unit of Vascular and Endovascular Surgery, Ibn Sina Specialized Hospital, Khartoum, Sudan.

Corresponding Author: Dr. Ahmed Mohamed Elhassan Elfaki Osman, Ward 17, Unit of Vascular and Endovascular Surgery, Department of Surgery, Ibn Sina Specialized Hospital, Alamarat, Khartoum, P.O. Box: 12217, Sudan; Ph: 00249-911718227; Email: ahmed710@hotmail.co.uk

Received: 30 November 2014

Accepted: 06 February 2015

Published: 30 March 2015 included all patients who present to the vascular surgery clinic and emergency department. Thirty patients had lower limb arterial injuries (LLAI). Data was collected using a structured checklist and analyzed using the SPSS program. Results: Twenty-seven (90\%) were male and three (10\%) were females. The most common age at presentation was $16-25$ years old $(43.3 \%)$, followed by 26-35 (26.7\%). The most common artery injured was the superficial femoral artery (SFA), $53.3 \%$ followed by the popliteal artery (6 patients; $20 \%$ ). Bullet injuries were the highest cause for LLAI, with an incidence rate of $36.7 \%$, while stab wounds presented at $23.3 \%$. Limb salvage rate was $\mathbf{7 6 . 7 \%}$, partially salvaged limb (forefoot amputation) rate was $16.7 \%$ and amputation rate was $6.6 \%$. Conclusion: Amputation rate was the highest in patients with SFA injuries. Appropriate intervention and rapid restoration of blood flow is crucial to have a good outcome and is key to successfully salvage the injured limb.

Keywords: Lower limb arterial injuries, Presentations, Management, Outcomes, Sudan

\section{How to cite this article}

Osman AMEE, Ibrahim SMA, Mokhtar AM, Mohamed GMH, Hassan SMY, Ahmed TER, Ali AHES. Lower limb arterial injuries-etiology, presentations, management and outcome: A center's experience. Edorium J Cardiothorac Vasc Surg 2015;2:8-18.

Article ID: 100004Co4AO2015

$$
* * * * * * * * *
$$

doi:10.5348/Co4-2015-4-OA-3 


\section{EDORIUM Journals}

Edorium J Cardiothorac Vasc Surg 2015;2:8-18.

www.edoriumjournalofctvs.com

\section{INTRODUCTION}

Lower limb injuries have attracted a lot of controversy over the past decades. They are injuries that result in much morbidity and functional deficit if not managed vigorously. An urgent intervention and restoration of blood flow to optimize functional outcome is the key to success. The decision to salvage limb versus amputation in the patient with major limb injuries should be individualized due to many factors involved [1].

The American College of Surgeons has classified the causes of vascular injuries usually encountered as: 1) penetrating wounds following bullet injuries, stab wounds or punctures; 2) blunt trauma due to joint displacement, bone fracture or contusion adjacent to major arteries; 3) invasive procedures such as arteriography, cardiac catheterization and balloon angioplasty [2].

There is evidence to support that surgery can be undertaken without performing angiography, and in some instances Doppler ultrasound as well. The 'hard signs of vascular injury' are those which demand rapid exploration, they include external arterial bleeding, rapidly expanding hematoma, palpable thrill, audible bruit and obvious arterial occlusion (pulseless limb, pallor, paresthesia, pain and paralysis). 'Soft signs', on the other hand, may be amenable for angiography or duplex scanning to determine whether or not surgical intervention will be needed; these signs are hematoma, history of hemorrhage at the scene of accident, unexplained hypotension and peripheral nerve deficit [2]. Broadly speaking, options for repair after assessment of vasculature include simple vessel wall repair, venous patching; resection with end-to-end anastomosis or with interpositioning graft, bypass graft, ligation or amputation. The type of repair to be undertaken depends on several factors, including, but not limited to, whether or not the artery involved is crucial for distal perfusion, the mode of trauma, the length of arterial injury, status of the posterior wall of the vessels (completely severed; $>50 \%$ intact), availability of autogenous or synthetic grafts and the overall condition of the limb distal to the site of arterial trauma. These repairs include: 1) ligation, 2) simple vessel wall repair, 3) patch angioplasty, 4) endto-end repair, 5) interposition grafting.

Ligation is the simplest type of repair and is usually well tolerated on the venous system, however, when an arterial injury is associated with a venous injury, the repair of the venous injury yields an improved outcome. In an unstable patient, selective arterial ligation may be considered because in some instances, sufficient collateral circulation can maintain distal tissue viability. With regards to the lower limb, the arteries that can be ligated are the internal iliac, SFA and one of the tibial arteries (if the pedal arch is intact) [3].

Simple vessel wall repair may be undertaken when an artery shows minimal damage, for example, if the injury is due to catheterization or a knife injury causing a clean laceration. It is not indicated in injuries caused by blunt trauma or bullet injuries [3]. Patch repair is indicated if more than $50 \%$ of the posterior wall of the injured artery is intact. However, it is advisable not to undertake this type of repair in an emergency setting; it is usually done on an elective repair [4]. End-to-end repair is superior to patch angioplasty in an emergency setting and is indicated if and adequate length of the injured artery remains to allow a tension free anastomosis. Resection of 1-2 cm of arterial length may be performed and still allow a tension free anastomosis. Advantages of an endto-end repair include the need for a single anastomosis, eliminating the need for harvesting an autogenous graft and synthetic material, and the long-term patency rate is higher than that of interposition grafting [5].

Interpositioning grafts are indicated when the length of an injured artery is inadequate to perform a tension free end-to-end anastomosis. Interpositioning grafts are either autogenous, harvested vein grafts or synthetic material and the indication for each depends on several factors. The choice is based on the size of both the artery to be reconstructed and the size of the available conduit to be used, the availability of a suitable vein for interpositioning, anatomic location of the artery, the level of contamination and the hemodynamic status of the patient [6].

Vascular damage control surgery is an extension of damage control laparotomy and is indicated when some injuries are too extensive to definitively repair on initial presentation. It has been shown that a damage control approach leads to a better outcome in patients with severe injuries that require long operating hours ( $>6$ hours). A temporary prosthetic shunt can be placed and the advantage of this type of bypass is that it allows a sooner return of the patient to return to the ICU for further resuscitation without compromising distal perfusion. The shunt is usually removed $1-2$ days later when the patient is more stable [7].

Performing fasciotomy is another form of salvaging the distal circulation and prophylactic extremity fasciotomy is strongly advised when more than four hours of warm ischemia time have passed [8].

\section{AIMS}

The general objective of this study is to identify the etiology, presentations, management and outcome of lower limb arterial injuries in Khartoum, Sudan, from Sept 2012 to Sept 2014.

Specifically, this study aims to assess the epidemiological factors of patients presenting with lower limb arterial injuries, such as age and gender as well as determining whether there is a common pattern of presenting complaints with regards to different types of arterial injuries. Furthermore, we carried out this study to investigate the outcome of the patients' limb with 


\section{EDORiUM Journals}

Edorium J Cardiothorac Vasc Surg 2015;2:8-18.

www.edoriumjournalofctvs.com

regards to the following factors: a) initial presentation and complaint, b) preoperative assessment of the patient, including, examination and preoperative investigations (Doppler ultrasound and CT angiography), and c) intraoperative arterial assessment and the procedure undertaken.

\section{MATERIALS AND METHODS}

The study design was a retrospective hospital based study and the study population included all patients who present to the vascular surgery clinic and emergency department. Thirty patients fit the criteria of presentation with lower limb arterial injury. Data were collected using a structured checklist and analyzed using the SPSS program.

Inclusion criteria included the following:

1) All patients admitted to the vascular surgery department with a history of lower limb trauma with suspected vascular injury, and

2) Patients with either "soft signs" or "hard signs" of vascular injury.

Exclusion criteria are:

1) patients with traumatic amputations

2) patients being tackled by non-vascular surgeons

\section{RESULTS}

In this study, thirty patients fit the criteria of lower limb arterial injuries (LLAI). Twenty-seven (90\%) were male patients while only three (10\%) were females as given in Table 1 .

The age at which the highest number of LLAI's were found was 16-25 years old (43.3\%), followed by 26-35 years old patients (26.7\%) as summarized in Table 2.

Table 1: Number of male and female patients with lower limb arterial injuries.

\begin{tabular}{lcc}
\hline Gender & Frequency & Percent \\
male & 27 & 90.0 \\
female & 3 & 10.0 \\
Total & 30 & 100.0 \\
\hline
\end{tabular}

Table 2: Age groups of patients who presented with lower limb arterial injuries.

\begin{tabular}{lll}
\hline Age & Frequency & Percent \\
\hline $10-15$ & 1 & $3 \cdot 3$ \\
$16-25$ & 13 & 43.3 \\
$26-35$ & 8 & 26.7 \\
$36-45$ & 6 & 20.0 \\
$>45$ & 2 & 6.7 \\
Total & 30 & 100.0 \\
\hline
\end{tabular}

With regards to the arteries injured, the most common artery injury was the superficial femoral artery (SFA), which were 16 injuries - 53.3\%, eight of these were amongst the age group of 16-25. The second commonest site of arterial injuries were at the popliteal artery (6 patients; 20\%). Regarding the time of presentation following initial injury, the majority of patients presented more than two weeks later $(33.3 \%)$, other presentation frequencies were $23.3 \%$ (6-12 hours), 13.3\% (1-7 days and 1-2 weeks), 10\% (1-6 hours) and 6.7\% (12-24 hours). Twenty-four patients suffered penetrating injuries (80\%) followed by five with blunt injury (16.7\%) and one patient had a crushing injury (3.3\%).

High velocity penetrating injuries (bullet injuries) were the highest cause for lower limb arterial injuries, with an incidence rate of $36.7 \%$, while stab wounds (low velocity injuries) presented at $23.3 \%$ of the times. Road traffic accidents came in second to high velocity penetrating injuries at $33.3 \%$ and only $6.7 \%$ of patients suffered arterial injuries due to iatrogenic causes (arterial catheterization).

Of these thirty patients, 21 were injured in the region of the thigh, thus explaining the commonness of the SFA injuries. Three were injured in the groin, and three in the calf while 2 were injured in the foot and one in the popliteal fossa.

The most common presenting complaint was swelling at the site of injury (60\%) followed by bleeding (40\%). Eleven patients had an associated bony injury.

During general assessment, 22 patients were in stage I shock (heart rate $=101-120$ beats per minute). Nineteen patients presented with normal blood pressure readings and 11 were hypotensive.

The distal pulses were absent in $80 \%$ of patients (24 patient) and gangrene was noted in 23.3\% (seven patients). Twelve patients (40\%) had some sort of neurological deficit (either motor or sensory loss, or both).

Doppler ultrasound assessment was done to 22 patients $(67.3 \%)$. The commonest finding was hematoma (33.3\%) followed by aneurysm (13.3\%), 6.7\% presented with both aneurysm and hematoma. Distal to the site of injury, blood flow was normal in one patient, minimal in 16 patients and absent in five patients. Eight patients were not assessed using Doppler ultrasound because we were called to see them while they were on the operating table; no Doppler ultrasounds were present at the time.

Regarding CT angiography, 13 patients were not sent for this investigation because of hemodynamic instabilities; a rapid exploration and control of bleeding was a necessity. For others, the presence of extending or overwhelming wet gangrene and the septic condition of the patient required urgent intervention. The common findings with the other patients were thrombosis + cutoff, which was found in $26.7 \%$ of patients followed by pseudoaneurysms which were seen in $16.7 \%$ of patients. Figure 1 shows an angiogram of a patient two months 


\section{EDORiUM Journals}

Edorium J Cardiothorac Vasc Surg 2015;2:8-18.

www.edoriumjournalofctvs.com

following a bullet injury with a severed popliteal artery and a fragmented femur.

Intraoperatively, the type of arterial injuries encountered were: completely severed (14 patients, 46.7\%), anterior wall traversing (13 patients, 43.3\%); posterior wall traversing (one patient, 3.3\%). Eight patients had an associated venous injury. One patient had a traumatic AVF (TAVF) and one had a spontaneously sealed TAVF. An organized hematoma was found and evacuated in 19 patients (63.3\%). The procedures performed are outlined in Table 3. Figure 2 shows a saphenous vein interpositioning graft done to a patient who presented with a lacerated superficial femoral artery.

Postoperatively, the limb salvage rate was $76.7 \%$, partial limb salvage (forefoot amputation) rate was $16.7 \%$ and amputation rate was $6.6 \%$. Figure 3 demonstrates an intact distal flow seen on a CT angiogram of a patient with an autogenous vein interpositioning graft.

Amputation rate was highest in patients with SFA injuries. Four out of the seven amputations were due to SFA injury, while the other three were due to popliteal artery injury; all of these patients had an associated gangrene which prompted the need for amputation. An algorithm suggesting an approach to extremity vascular injuries is outlined in Figure 4.

\section{DISCUSSION}

Ashworth et al. did a study encompassing 25 patients who presented with lower limb vascular injuries, they found that the majority of the patients were young males injured by penetrating trauma. There was a total of 37 vascular injuries, 25 were arterial and 12 venous, two of

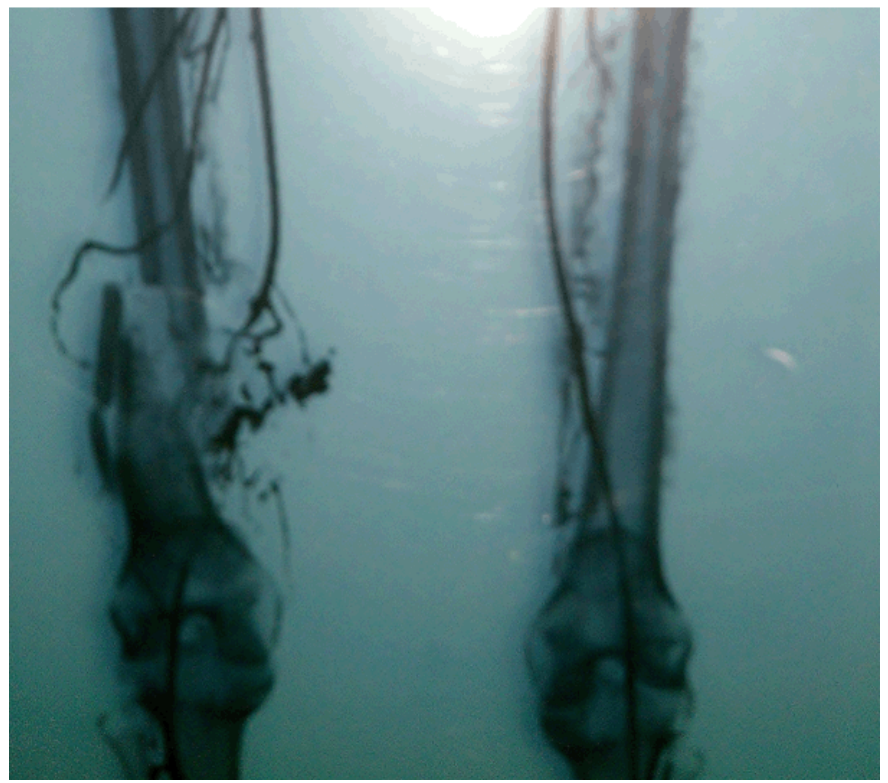

Figure 1: Computed tomography angiogram of a patient presenting two months following a bullet injury showing a severed popliteal artery and a fragmented femur.
Table 3: Procedures performed for patients who presented with lower limb arterial injuries.

\begin{tabular}{lll} 
Procedure & Frequency & Percent \\
\hline Proximal embolectomy & 19 & 63.3 \\
Distal Embolectomy & 20 & 66.7 \\
Simple vessel wall repair & 3 & 10 \\
AVF ligation & 1 & 3.3 \\
Autogenous bypass graft & 17 & 56.7 \\
Synthetic bypass graft & 7 & 23.3 \\
Aneurysmectomy & 6 & 20 \\
Amputation & 7 & 23.3 \\
\hline
\end{tabular}

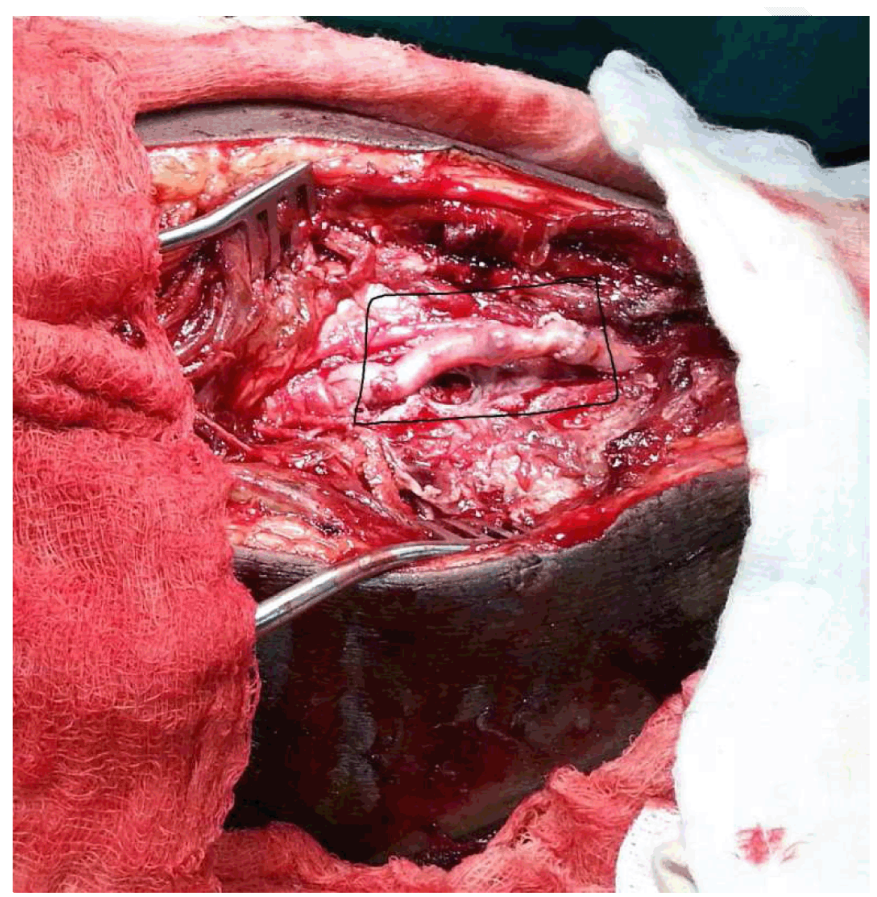

Figure 2: Saphenous vein interposition graft of a superficial femoral artery (SFA) stab wound injury.

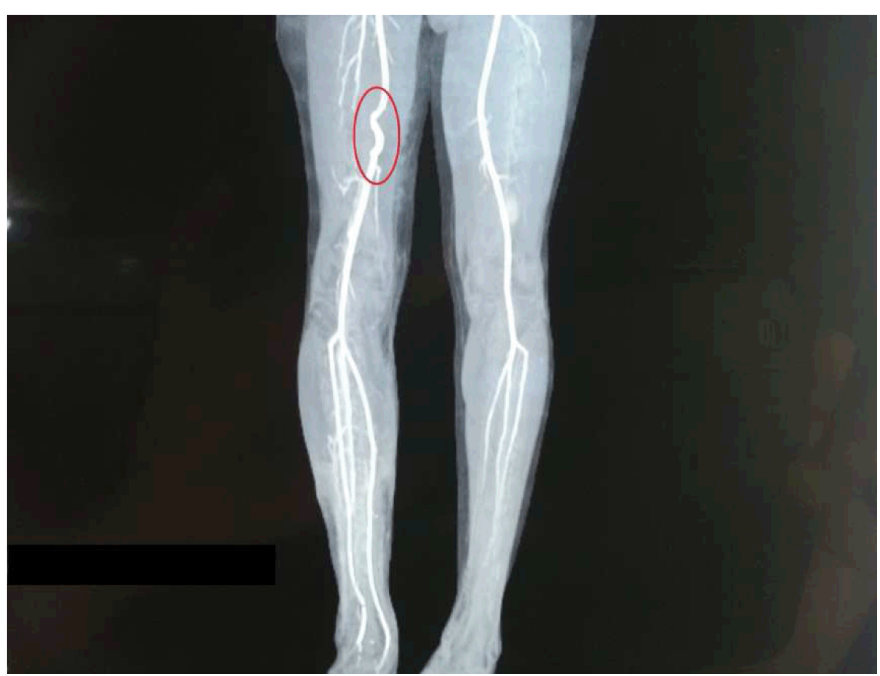

Figure 3: Computed tomography angiogram showing an autogenous vein interpositioning graft (red circle) at the right superficial femoral artery and an intact distal circulation. 


\section{EDORIUM Journals}

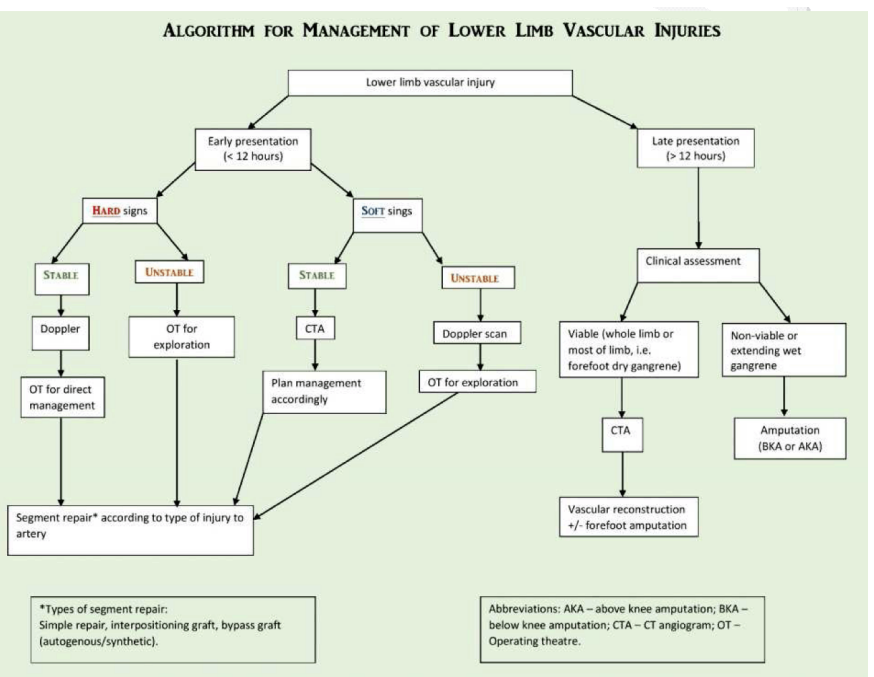

Figure 4: Algorithm for management of extremity vascular injuries.

which were isolated venous injuries [9]. Our study yielded similar results, encompassing 30 patients with vascular injuries, we saw that the majority of the patients were young males $(16-25$ years old $=43 \%$ and $26-35$ years old $=27 \%)$. The frequency of penetrating trauma was also high in this study (80\%).

In their study, 22 arterial injuries were repaired, 17 of these injuries using a saphenous vein bypass. Their limb salvage rate was $96 \%$ and independent ambulation rate on the injured extremity is $84 \%$. They concluded that an aggressive approach to lower limb vascular injuries is necessary, as supported by their findings [9]. With regards to arterial repairs carried out by our center over one year, 27 arterial injuries were repaired - three simple vessel wall repairs, 17 autogenous saphenous vein interpositioning grafts and seven using synthetic PTFE grafts. Although an aggressive approach was carried out, the limb salvage rate was $76.7 \%$ which is due to several factors that will be addressed in the conclusion.

In a case series study conducted by Siddique et al., which the objective was "to describe the different presentations, diagnostic evaluation, management and outcome of complications of missed vascularinjuries", they studied 28 patients who presented with missed vascular injuries over a span of three years. The male to female ratio was six to one. The majority of patients presented with pseudoaneurysm alone (12 patients), followed by 10 with AVF, 4 with post traumatic thrombosis and 2 with pseudoaneurysm and hemorrhage. The commonest type of injury was penetrating injury and the time of presentation after initial injury ranged from 2 to 1300 weeks. The most frequently involved artery in their study was the superficial femoral artery, with an incidence of $32.1 \%$ (9 patients), and the commonest repair undertaken was a saphenous vein bypass. Amputation rate was $3.5 \%$ (one patient) [10]. In our study, the male to female ratio was nine to one. The high occurrence of male admissions was due to stab wound injuries and RTA's, while two of the females suffered iatrogenic vascular injuries, only one was involved in a RTA. The commonest presentation was swelling at the site of injury (60\%) followed by bleeding (40\%) and 11 patients had an associated bony injury. With regards to the type, again, the results are similar. The time by which patients presented to our center with a diagnosis of possible vascular injuries was more than two weeks for the majority of patients (33.3\%).

In a 10 year study conducted by Hafez et al., regarding lower limb arterial injuries, they concluded that lower limb arterial injuries carry a high amputation rate (16.2\% as outlined by their study) and limb salvage rate was $83.8 \%$. They also concluded that the relation between high velocity penetrating injuries and amputation was higher when compared to low velocity penetrating injuries. Their most significant independent factor for limb loss was failed revascularization [11]. Amputation rates carried out in our center due to LLAI's was $76.7 \%$, although if we subcategorize our amputations as salvaged, partially salvaged (forefoot amputations) and amputated limbs, we notice that the above knee amputation rates are $6.7 \%$ and the partially salvaged limb (forefoot amputations) is $16.7 \%$.

Singh et al. studied the management of peripheral vascular trauma in 662 patients in a time span ranging 12 years, which included both upper and lower extremity arterial injuries. Their results concluded that $88 \%$ of affected patients were male and the mean duration of presentation was 10 hours following injury.

The commonest mode of trauma was penetrating trauma with an incidence rate of $70 \%$, followed by blunt trauma which was $52 \%$. The commonest lower limb artery injured in this study was the popliteal artery (29.7\%). Primary vessel repair was done in $55.5 \%$ of patients and an interpositioning autogenous vein graft was done in $35.2 \%$ of patients [12]. This study again concurs with the results of our study with regards to the gender and mode of trauma, however, the commonest injured artery in our study was the superficial femoral artery (53.3\%) followed by popliteal artery injuries (20\%). Simple vessel wall repair was carried out in only $10 \%$ of the patients while $56.7 \%$ had an autogenous interpositioning graft and $23.3 \%$ were revascularized using a PTFE graft.

With regards to the rate of amputation versus salvaged limbs, amputation increased gradually after the first 24 hours (Table 4) with no amputations carried out in patients who presented less than 24 hours after their initial injury.

The highest rate of amputation was in patients who presented with vascular injuries due to road traffic accidents (five out of seven amputees) followed by patients who presented with bullet injuries (2 amputees) (Table 5). 


\section{EDORiUM Journals}

Edorium J Cardiothorac Vasc Surg 2015;2:8-18.

www.edoriumjournalofctvs.com

Table 4: Amputation rates versus time of presentation after initial injury

\begin{tabular}{|c|c|c|c|c|c|c|c|}
\hline \multicolumn{8}{|c|}{ Time of presentation after initial injury } \\
\hline & & $\begin{array}{c}1-6 \\
\text { hours }\end{array}$ & $\begin{array}{c}\text { 6-12 } \\
\text { hours }\end{array}$ & $\begin{array}{c}12-24 \\
\text { hours }\end{array}$ & $\begin{array}{c}1-7 \\
\text { days }\end{array}$ & $\begin{array}{c}1-2 \\
\text { weeks }\end{array}$ & $\begin{array}{c}>2 \\
\text { weeks }\end{array}$ \\
\hline & done & o & o & o & 1 & 2 & 4 \\
\hline Amputation & $\begin{array}{c}\text { not } \\
\text { done }\end{array}$ & 3 & 7 & 2 & 3 & 2 & 6 \\
\hline
\end{tabular}

Table 5: Amputation rates with regards to mode of injury

\begin{tabular}{|ccccccc} 
& & \multicolumn{5}{c}{ Mode of Injury } \\
\cline { 3 - 6 } & & $\begin{array}{c}\text { Stab } \\
\text { wound }\end{array}$ & $\begin{array}{c}\text { Bullet } \\
\text { injury }\end{array}$ & RTA Iatrogenic* & Total \\
Amputation & $\begin{array}{c}\text { done } \\
\text { not } \\
\text { done }\end{array}$ & 0 & 2 & 5 & 0 & 7 \\
\hline
\end{tabular}

Performa for collecting data such as causes, presentations and outcomes of lower limb arterial injuries

PERSONAL DATA

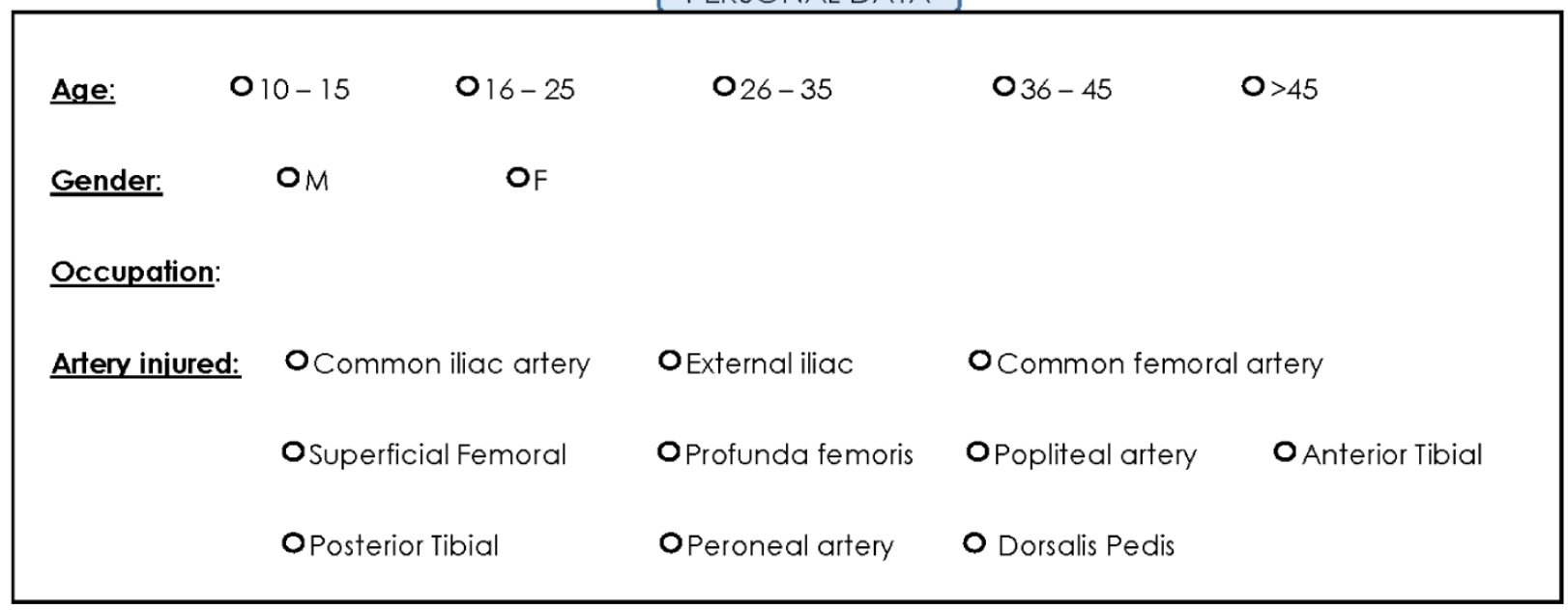

\section{PRESENTATION}

\section{Time of presentation after initial iniury:}

$\mathbf{0}<1$ hour $\quad 01-6$ hours $\quad 06-12$ hours $\quad 012-24$ hours $\quad 0<7$ days $\quad 01-2$ weeks
$\mathbf{0}>2$ weeks

\section{Mode of trauma:}

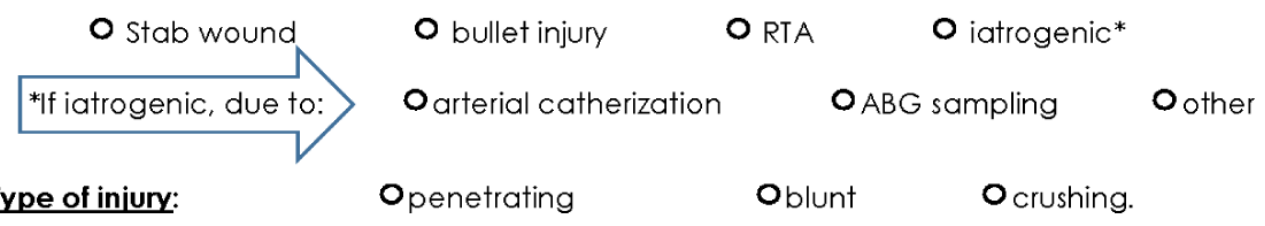
Site of iniury:
groin
OThigh
O popliteal fossa
o calf
o foot
O multiple

Presenting complain: Oswelling Obleeding Ohypovolemic shock

Ogangrene $\quad$ ocompartment syndrome

Associated iniuries: Ofracture Osoft tissue injury Onerve injuries $\mathbf{O}_{\text {venous injury }}$ 


\section{EDORiUM Journals}

Edorium J Cardiothorac Vasc Surg 2015;2:8-18.

www.edoriumjournalofctvs.com

EXAMINATION

\section{Vitals:}

- Pulse (bpm): $\quad \begin{array}{llll}\mathbf{0}<100 & \mathbf{0 1 0 1 - 1 2 0} & \mathbf{0 1 2 1 - 1 4 0} & \mathbf{0}>140\end{array}$

- BP: Owithin normal limits Ohypotensive
local examination: OBleeding
Olocalized swelling (pulsatile)
Othrill
O Tenderness (compartment syndrome)
O open femoral fracture
O Knee dislocation $\quad$ Open tibial/fibula fracture

\section{Regional examination:}

- Distal pulses: Opresent Oabsent

- Gangrene: Oyes Ono

- Motor/sensory loss: Oyes Ono

INVESTIGATIONS

\section{Doppler:}
At site of injury:
OAneurysm
Ohematoma

Flow distal to injury:

Onormal

Ominimal

Oabsent

\section{CT-angiogram:}

OThrombosis + cut-off

OAneurysm

Osevered artery

OAVF

INTRAOPERATIVELY

\section{Type of artery iniury:}

OTraversing: Oanterior wall Oposterior wall

O Completely severed
Associated femoral vein iniury:
Oyes
Ono

Iraumatic AVF:

Oyes

Ono

Osealed due to venous thrombus formation

Organized hematoma:

Oyes

Ono 


\section{EDORiUM Journals}

Edorium J Cardiothorac Vasc Surg 2015;2:8-18.

www.edoriumjournalofctvs.com

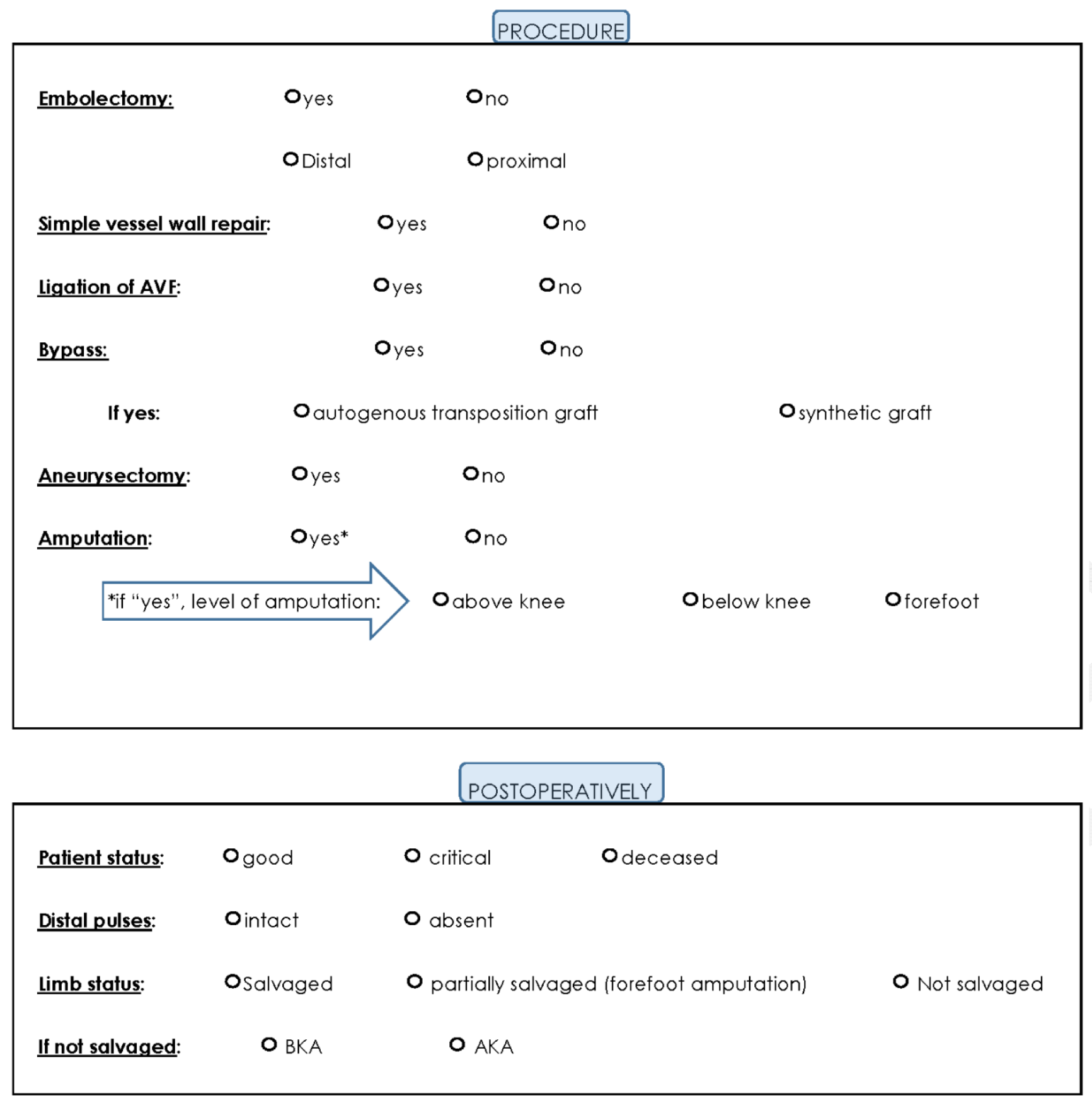

\section{CONCLUSION}

In conclusion, lower limb injuries are injuries that result in considerable morbidity and lifestyle deterioration if a prompt, energetic and dynamic approach is not carried out. Intervention and a rapid restoration of blood flow is critical to optimize functional outcome and is key to a successful salvage of both the patient and the limb. The nature by which males and females suffer arterial injuries and the high ratio of male to female vascular injuries (9:1) can logically be explained by the mode of trauma - stab and bullet injuries mostly amongst young males whilst arterial catheterization and a RTA for females. Delayed presentation is the fundamental cause to amputation in our study. The delay in presentation may be from lack of healthcare professionals and public awareness towards injuries involving the vascular system. The lack of vascular surgeons in Sudan also is a contributing factor to delays in presentation and referral difficulties - with only a handful of vascular surgeons serving the country as a whole. The key to avoiding amputations in extremity trauma is to increase the awareness of healthcare professionals with regards to issues concerning the approach, appropriate resuscitation and prompt referral of patients. 


\section{EDORiUM Journals}

Edorium J Cardiothorac Vasc Surg 2015;2:8-18.

www.edoriumjournalofctvs.com

\section{Author Contributions}

Ahmed M.E.E. Osman - Conception and design, Acquisition of data, Analysis and interpretation of data, Drafting the article, Critical revision of the article, Final approval of the version to be published

Saif Eldin Mohammed Ali Ibrahim - Conception and design, Acquisition of data, Critical revision of the article, Final approval of the version to be published

Ashraf Mohammed Mokhtar - Conception and design, Drafting the article, Final approval of the version to be published

Ghofran Mahgoub Hussien Mohamed - Analysis and interpretation of data, Drafting the article, Final approval of the version to be published

Sara Mohammed Yassin Hassan - Conception and design, Drafting the article, Final approval of the version to be published

Tasneem Elrayah Ramli Ahmed - Acquisition of data, Analysis and interpretation of data, Drafting the article, Final approval of the version to be published

Abubakr Hashim Elrofaie Sayed Ali - Analysis and interpretation of data, Critical revision of the article, Final approval of the version to be published

\section{Guarantor}

The corresponding author is the guarantor of submission.

\section{Conflict of Interest}

Authors declare no conflict of interest.

\section{Copyright}

(C) 2015 Ahmed M.E.E. Osman et al. This article is distributed under the terms of Creative Commons Attribution License which permits unrestricted use, distribution and reproduction in any medium provided the original author(s) and original publisher are properly credited. Please see the copyright policy on the journal website for more information.

\section{REFERENCES}

1. Langer V. Management of Major Limb Injuries. ScientificWorldJournal 2014:640430.

2. Feliciano DV. Management of peripheral vascular trauma. American College of Surgeons. Committee on Trauma. Subcommittee on publications 2002. Found at:https://www.facs.org/ /media/files/ quality\%2oprograms/trauma/publications/ peripheralvasctrauma.ashx

3. Gerald B Zelenock et al. Mastery of Vascular and Endovascular Surgery, 2006; section V (Vascular Trauma); Chapter 77 (Management Principle for Vascular Trauma); Pg 615-6.

4. Brohi K. Patch Angioplasty. Atlas of Trauma (trauma. org) 7:12.
5. Ball CG, Feliciano DV. A simple and rapid vascular anastomosis for emergency surgery: A technical case report. World J Emerg Surg 2009 Aug 3;4:30.

6. Feliciano DV. Vascular, Interposition Grafts. Encyclopedia of Intensive Care Medicine 2012:23946.

7. Rasmussen TE, Clouse WD, Jenkins DH, Peck MA, Eliason JL, Smith DL. The use of temporary vascular shunts as a damage control adjunct in the management of wartime vascular injury. $J$ Trauma $2006 \mathrm{Jul} ; 61(1): 8-12$.

8. Farber A, Tan TW, Hamburg NM, et al. Early fasciotomy in patients with extremity vascular injury is associated with decreased risk of adverse limb outcomes: A review of the National Trauma Data Bank. Injury 2012 Sep;43(9):1486-91.

9. Ashworth EM, Dalsing MC, Glover JL, Reilly MK. Lower Extremity Vascular Trauma: A Comprehensive, Aggressive Approach. J Trauma 1988 Mar;28(3):3296.

10. Siddique MK, Majeed S, Irfan M, Ahmad N. Missed vascular injuries: Presentation and outcome. J Coll Physicians Surg Pak 2014 Jun;24(6):428-31.

11. Hafez HM, Woolgar J, Robbs JV. Lower extremity arterial injury: Results of 550 cases and review of risk factors associated with limb loss. J Vasc Surg 2001 Jun;33(6):1212-9.

12. Singh D, Rk P. Management of Peripheral Vascular Trauma: Our Experience. The Internet Journal of Surgery 2004;7(1). 


\section{EDORiUM Journals}

Edorium J Cardiothorac Vasc Surg 2015;2:8-18.

www.edoriumjournalofctvs.com

\section{ABOUT THE AUTHORS}

Article citation: Osman AMEE, Ibrahim SEMA, Mokhtar AMM, Mohamed GMH, Hassan SMY, Ahmed TER, Ali AHES. Lower limb arterial injuries-etiology, presentations, management and outcome: A center experience. Edorium J Cardiothorac Vasc Surg 2015;2:8-18.

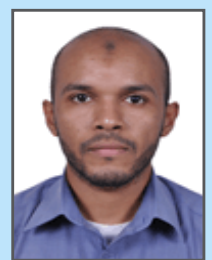

Ahmed Mohamed Elhassan Elfaki Osman has been a Vascular and Endovascular Surgery Resident at Sina specialized hospital in Khartoum, Sudan, since September 2013. He earned his undergraduate (MBBS) degree from the National Ribat University in Sudan. He intends to pursue a vascular surgery integrated residency in the US as well as a research career in vascular biology and tissue regeneration in the future.

E-mail: ahmed710@hotmail.co.uk

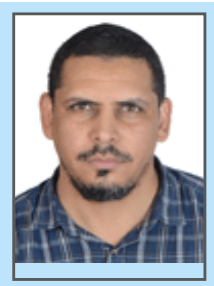

Saif Eldin Mohammed Ali Ibrahim [MD, MRCS (ENG); D.MAS; F.MAS; F. Vasc/Endovasc (MAL)] is a Consultant Vascular and Endovascular Surgeon as well as the Head of the unit of Vascular and Endovascular Surgery at Ibn Sina Specialized Hospital in Khartoum, Sudan. He earned MBBS degree from the University of Khartoum, Sudan and postgraduate (MD) degree from Sudan. Dr. Ibrahim obtained his Vascular and Endovascular Surgery fellowship from Malaysia. He also completed fellowships in Minimal Access Surgery as well as Robotic Surgery.

E-mail: saif_ibrahim20oo@yahoo.com

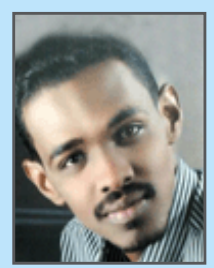

Ashraf Mohamed Mokhtar Ali is a General Surgeon and a Vascular Surgery Specialist at Vascular and Endovascular surgery unit, Ibn Sina Specialized Hospital in Khartoum, Sudan. He earned his undergraduate degree (MBBS) from university of Gezira, Sudan, and postgraduate MD in general surgery from Sudan.

E-mail: 0912352024a@gmail.com

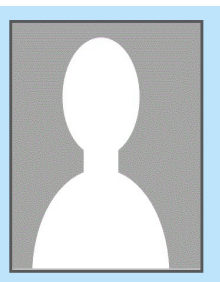

Ghofran Mahgoub Hussien Mohamed is a Vascular and Endovascular Surgery Resident at Ibn Sina Specialized Hospital in Khartoum Sudan. She obtained her MBBS degree from the University of Khartoum in 2012. She will be starting a general surgery MD this year in Sudan and intends to pursue a career in Vascular and Endovascular surgery in the future.

E-mail: ghofranmahgoub@yahoo.com

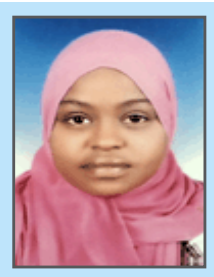

Sara Mohammed Yassin Hassan has been a vascular and endovascular surgery resident at Sina specialized hospital in Khartoum, Sudan, since June 2013. She earned undergraduate (MBBS) degree from the Khartoum College of Medicine in 2011. She intends to pursue a career in vascular surgery focused mainly on endovascular interventions.

E-mail: sarayassin58@hotmail.com

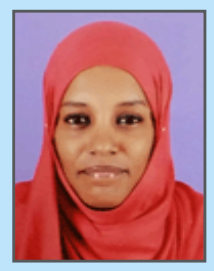

Tasneem Elrayah Ramli Ahmed has been a Vascular and Endovascular surgery resident at Ibn Sina Specialized Hospital since April 2014. She obtained MBBS degree from Upper Nile University in Sudan.

E-mail: tasneemramli@hotmail.com

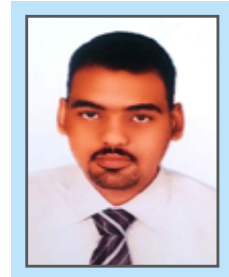

Abubakr Hashim Elrofaie Sayed Ali is a Resident of Vascular and Endovascular Surgery unit, Ibn Sina specialized Hospital in Khartoum, Sudan. He earned MBBS degree from the National Ribat university in Sudan. He intends to pursue clinical career in vascular and cardiothoracic surgery as well as educational and research position in the future.

E-mail: abubakrelrofaie@gmail.com 


\section{EDORiUM Journals}

Edorium J Cardiothorac Vasc Surg 2015;2:8-18.

Access full text article on other devices

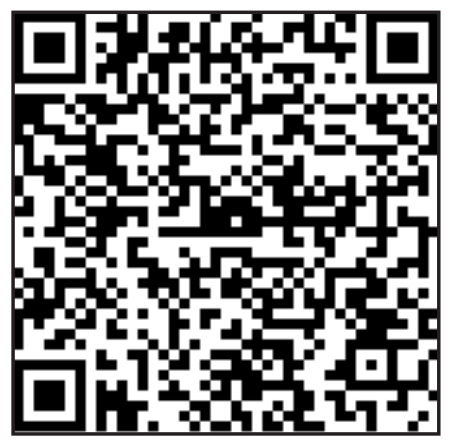

Access PDF of article on other devices

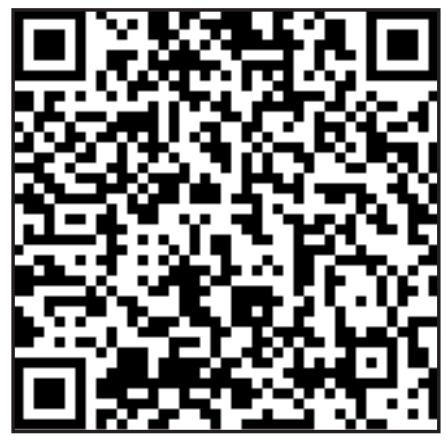

